\title{
Ambient Levels of TSP, PM10, PM2.5 and Particle Number Concentration in Al Samha, UAE
}

\author{
Fadi A. Al-Jallad ${ }^{1,2 *}$, Clarence C. Rodrigues ${ }^{1}$, Hamda A. Al-Thani ${ }^{2}$ \\ ${ }^{1}$ Health, Safety and Environment Department, The Petroleum Institute, Abu Dhabi, UAE \\ ${ }^{2}$ National Energy and Water Research Center, Abu Dhabi Water and Electricity Authority, Abu Dhabi, UAE \\ Email: faljallad@pi.ac.ae
}

How to cite this paper: Al-Jallad, F.A., Rodrigues, C.C. and Al-Thani, H.A. (2017) Ambient Levels of TSP, PM10, PM2.5 and Particle Number Concentration in Al Samha, UAE. Journal of Environmental Protection, 8, 1002-1017.

https://doi.org/10.4236/jep.2017.89063

Received: June 6, 2017

Accepted: August 21, 2017

Published: August 24, 2017

Copyright (c) 2017 by authors and Scientific Research Publishing Inc. This work is licensed under the Creative Commons Attribution International License (CC BY 4.0).

http://creativecommons.org/licenses/by/4.0/

\section{c) (i) Open Access}

\begin{abstract}
The Arabian Peninsula experiences elevated levels of airborne particulate originated from both natural and anthropogenic sources. This study is mainly aimed to determine the ambient levels of TSP, $\mathrm{PM}_{10}$ and $\mathrm{PM}_{2.5}$ ) at one of the monitoring locations "Al Samha" that is located in the northeast quadrant of UAE. Mass concentrations, particle count, as well as meteorological parameters were simultaneously measured using a spectrometer, $\mathrm{PM}_{10}$ beta attenuation monitor and weather sensors for the period from April 10 to December 31, 2011. The hourly mean concentrations of TSP, $\mathrm{PM}_{10}, \mathrm{PM}_{2.5-10}$ and $\mathrm{PM}_{2.5}$ were $245,110,64$ and $46 \mu \mathrm{g} / \mathrm{m}^{3}$, respectively. About $34 \%, 15 \%$ and $56 \%$ of the monitored days had daily concentrations above the allowable limits for TSP, $\mathrm{PM}_{10}$ and $\mathrm{PM}_{2.5}$, respectively. Diurnal peak occurred at 14:00 for TSP, at 10:00 for $\mathrm{PM}_{10}$, and at 04:00 for $\mathrm{PM}_{2.5}$ reaching values of up to 410,122 , and $54 \mu \mathrm{g} / \mathrm{m}^{3}$, respectively. The highest concentrations were observed on Saturdays for TSP and $\mathrm{PM}_{10}$, but on Sundays for $\mathrm{PM}_{2.5}$. July had the greatest monthly level of PM compared to other months of this study. The average ratios of $\mathrm{PM}_{10} / \mathrm{TSP}, \mathrm{PM}_{2.5} / \mathrm{TSP}$ and $\mathrm{PM}_{2.5} / \mathrm{PM}_{10}$ were $0.61,0.31$ and 0.47 , respectively. Weak relationships were found between the particle number and mass concentrations, while very strong to moderate correlations were observed among all PM size fractions as well as between TSP and wind speed. The measurement results of the light scattering spectrometer were strongly correlated with the beta attenuation monitor, but the mean value of the spectrometer was higher by $18 \%$.
\end{abstract}

\section{Keywords}

Particulate Matters, Meteorological Parameters, Correlation 


\section{Introduction}

Air pollution kills about 7 million people, $12.5 \%$ of the global deaths, every year across the world [1], and it is expected to become the top environmental cause of global mortality by 2050 [2]. Predominantly, airborne particulates contribute greatly to poor air quality and are considered to be one of the biggest threats to human health in urban environments [3] [4] [5] [6] [7].

Airborne particulate can be classified in various ways based on their properties such as; size, shape, formation mechanism, and composition. However, the most common classification is according to their characteristic size [8]. Total Suspended Particles (TSP) refers to all particles up to 50 micrometers $(\mu \mathrm{m})$ in diameter that can remain suspended in the atmosphere for significant periods of time [9]. More precisely, Particulate Matter (PM) is usually labeled by a number indicating its aerodynamic diameter. For instance, $\mathrm{PM}_{10}$ (respirable) and $\mathrm{PM}_{2.5}$ (fine) refer to particles with a nominal mean aerodynamic diameter of less than or equal to $10 \mu \mathrm{m}$ and $2.5 \mu \mathrm{m}$, respectively [10]. The notation $\mathrm{PM}_{2.5-10}$ is used to represent the coarse particles with an aerodynamic diameter between $2.5 \mu \mathrm{m}$ and $10 \mu \mathrm{m}$ [11].

The sources of PM are divided into three major categories; natural, anthropogenic and secondary. Windblown dust, sea sprays, volcanoes, fires and pollen are examples of natural sources. On the other hand, anthropogenic sources are further classified into stationary and mobile subcategories; stationary sources are fixed-site producers such as power plants, factories, mines, farms, and waste-disposal sites. Whereas, mobile sources are mainly the transportation means such as cars, trucks, planes and ships that emit pollutants while moving [12]. Finally, secondary fine particles are formed in the atmosphere through chemical reactions among the gaseous pollutants involving; sulfur dioxide $\left(\mathrm{SO}_{2}\right)$, nitrogen oxides $\left(\mathrm{NO}_{\mathrm{x}}\right.$ ), volatile organic compounds (VOCs) and ammonia $\left(\mathrm{NH}_{3}\right)$ [13].

Elevated levels of ambient PM might lead to considerable adverse effects on public health and the environment. On one hand, it contributes to visibility degradation, acid deposition, and influences the climate either directly by scattering and absorbing sunlight radiation or indirectly through providing condensation nuclei for cloud droplets [14]. On the other hand, both short and long-term exposures to PM cause respiratory and cardiovascular diseases and are also linked to overall increased mortality [15]. However, the size of the particle plays an important role in its potential hazard. As such, smaller particles have a larger surface area available for physical and chemical interactions, travel farther distances, remain suspended for longer times, and penetrate deeper into the human respiratory system [16].

Therefore, strategic plans have been developed and implemented by many countries across the world to control PM levels and eventually minimize its adverse impacts [17]. In order to achieve the desired objectives, these control plans should be established based on reliable monitoring information, which highlights the importance of assessment and evaluation programs [18].

The Arabian Peninsula, including the United Arab Emirates (UAE), experiences elevated levels of PM originating from both natural and anthropogenic 
sources [19] [20] [21]. Thus, comprehensive studies are very essential to understand the temporal and the spatial behavior of the suspended particulates, and to accordingly apply effective measures to achieve and maintain acceptable levels.

In this study, continuous measurements were carried out at $\mathrm{Al} \mathrm{Samha}$ area for TSP, $\mathrm{PM}_{10} \& \mathrm{PM}_{2.5}$ mass concentrations, particle count as well as meteorological parameters during the period from April 10 to December 31, 2011. The obtained results were comprehensively analyzed to examine different measurement techniques, verify the compliance with relevant standards, determine temporal variation patterns, and investigate inter-correlations between the measured parameters. The findings of this study might be of great relevance to scientists and decision-makers, providing them with a fundamental basis to establish further research studies and develop effective policies for pollution reduction.

\section{Material and Methods}

\subsection{Site Description}

The measurements were conducted in Al Samha area (Figure 1), which is located approximately $40 \mathrm{~km}$ northeast of Abu Dhabi City at about the midway to



Figure 1. Map showing the location of the study area. 
Dubai. The area is surrounded by various contributors of particulate matters, from sources such as desert sand, power plants, an aluminium smelter, and construction activities, in addition to road and sea traffic. Furthermore, sandstorms are a common occurrence across the entire region, especially during the summer months.

The UAE generally has a subtropical and arid climate, being hot, humid and very dry during summer (April to September), and becoming cooler with occasional rainfall during the winter season (October to March) [22].

\subsection{Instrumentation}

In this study, TSP, $\mathrm{PM}_{10}, \mathrm{PM}_{2.5}$ mass concentrations and Particle Number (PN) were simultaneously measured using a Grimm aerosol spectrometer (Grimm Aerosol Technik GmbH, Germany, model EMD 365), which is also equipped with weather sensors (LufftGmbH, Germany, model WS600) to jointly monitor meteorological parameters such as wind speed, wind direction, relative humidity and temperature. The mass concentrations of the coarse particles $\left(\mathrm{PM}_{2.5-10}\right)$ were calculated as the difference between $\mathrm{PM}_{10}$ and $\mathrm{PM}_{2.5}$ concentrations. Concurrently, $\mathrm{PM}_{10}$ mass concentrations were measured continuously using a beta attenuation monitor (Environment S.A., France, model MP101M). For comparison and verification purposes, TSP and $\mathrm{PM}_{2.5}$ daily levels were also gravimetrically determined by collecting of some random samples.

The spectrometer (EDM 365) is designed on the principle of orthogonal light scattering, where air containing multiple particle sizes passes through a flat laser beam. The scattered signal is collected at approximately $90^{\circ}$ to the beam by a mirror and is detected by a high speed photodiode. Each signal is then counted and classified into different size channels by an integrated pulse height analyzer. Eventually, these counts are converted to a mass distribution using the density factor established for urban environments. The EDM 365 utilizes a diffusion dryer to avoid condensation during measurement, which is activated when the relative humidity exceeds $70 \%$. In the beta attenuation monitor, the sampling stream is slightly heated to avoid water condensation, and the air sample is sucked at a constant flow rate $(16.7 \mathrm{~L} / \mathrm{min})$ from $\mathrm{PM}_{10}$ size-selective inlet and pulled through a filter to deposit particles. At the end of a predefined hourly sampling cycle, the loaded filter is positioned between a carbon 14 beta source and a Geiger-Mueller detector to determine attenuation of the beta ray signal which is directly proportional to the mass of dust accumulated on the filter.

Finally, a particulate sampler (Environment S.A., France, model MP162) was used to collect daily random samples of TSP and $\mathrm{PM}_{2.5}$, where an air sample is drawn for 24 hours at a constant flow rate of $16.7 \mathrm{~L} / \mathrm{min}$ through a size-selective inlet (TSP or $\mathrm{PM}_{2.5}$ ) and then collected on a $47 \mathrm{~mm}$ filter membrane. The filters were conditioned and weighted prior and after sampling to determine net weight gain due to the collection of sample and eventually estimate the concentration.

\subsection{Regulations and Guidelines}

Air quality standards for suspended PM have been established by different entities 
in order to protect public health and the environment (Table 1). These standards identify the maximum acceptable concentrations in ambient air, which should not be exceeded during a specified time interval. In this study, the UAE standards were used to assess the daily concentrations of TSP and $\mathrm{PM}_{10}$, while the $\mathrm{PM}_{2.5}$ daily limit of $35 \mu \mathrm{g} / \mathrm{m}^{3}$ was also consulted since it is widely applied in many countries such as the Kingdom of Saudi Arabia (KSA), United States (USA) and others.

Table 1. Ambient air quality standards for airborne particles $\left(\mu \mathrm{g} / \mathrm{m}^{3}\right)$.

\begin{tabular}{cccccc}
\hline Max Allowable Limit & UAE & $\begin{array}{c}\text { Saudi } \\
\text { Arabia }\end{array}$ & WHO & US-EPA & $\begin{array}{c}\text { European } \\
\text { Union }\end{array}$ \\
\hline TSP & 230 & - & - & - & 150 \\
Daily & 90 & - & - & - & - \\
Annual & 150 & $340^{*}$ & 50 & 150 & 50 \\
PM $_{10}$ & - & 80 & 20 & - & 40 \\
Daily & & & & & \\
Annual & - & $35^{*}$ & 25 & $35^{*}$ & - \\
PM & 15 & 10 & 15 & 25 \\
Daily & - & & & & \\
Annual & & & & & \\
\hline
\end{tabular}

*Based on a percentile value.

\subsection{Statistical Analysis}

All statistical analyses were performed using Microsoft Excel and SPSS Statistics. Pearson's correlation analysis was used to determine the linear correlations between the measured parameters, where the existence and strength of the relationship is assessed based on the correlation coefficient ( $r)$ as follows: negligible if $r<0.19$, weak if $r$ is between 0.2 and 0.39 , moderate if $r$ is between 0.4 and 0.59 , strong if between 0.6 and 0.79 , and very strong if $r>0.8$ [23].

\section{Results and Discussion}

\subsection{Mass Concentrations and Particle Number}

Descriptive statistics of the hourly concentrations obtained throughout the study period are summarized in Table 2 . Based on mean value, TSP was approximately 2.2, 3.8 and 5.3 times greater than $\mathrm{PM}_{10}, \mathrm{PM}_{2.5-10}$ and $\mathrm{PM}_{2.5}$, respectively; while $\mathrm{PM}_{10}$ was higher than $\mathrm{PM}_{2.5-10}$ by a factor of 1.7 and $\mathrm{PM}_{2.5}$ by a factor of 2.4 . Hourly concentrations of the particulate number varied widely from $34,035 \mathrm{~cm}^{-3}$ to $2,085,556 \mathrm{~cm}^{-3}$ with a median of $247,431 \mathrm{~cm}^{-3}$.

Table 2. Statistical analysis results for measurements of hourly concentration conducted during the study period.

\begin{tabular}{cccccc}
\hline \multirow{2}{*}{ Datum } & TSP & PM $_{10}$ & PM $_{2.5-10}$ & PM $_{2.5}$ & PN \\
\cline { 2 - 6 } & \multicolumn{7}{c}{$\left(\mu \mathrm{g} \cdot \mathrm{m}^{-3}\right)$} & $\left(\mathrm{cm}^{-3}\right)$ \\
\hline Min & 20 & 12 & 2 & 6 & 34,035 \\
Max & 4496 & 967 & 601 & 409 & $2,085,556$ \\
\hline
\end{tabular}




\section{Continued}

\begin{tabular}{cccccc}
\hline Median & 147 & 83 & 43 & 38 & 247,431 \\
Mean & 245 & 110 & 64 & 46 & 302,985 \\
Stand. Deviation & 317 & 94 & 66 & 34 & 212,882 \\
$98^{\text {th }}$ Percentile & 1164 & 399 & 278 & 140 & 924,524 \\
\hline
\end{tabular}

As shown in Figure 2, elevated daily concentrations were observed during the study period for TSP, $\mathrm{PM}_{10}$ and $\mathrm{PM}_{2.5}$ reaching values of up to $1160 \mu \mathrm{g} / \mathrm{m}^{3}, 657$ $\mu \mathrm{g} / \mathrm{m}^{3}$ and $252 \mu \mathrm{g} / \mathrm{m}^{3}$, respectively. Furthermore, about $34 \%, 15 \%$ and $56 \%$ of the monitored days had 24-hour average concentrations above the maximum allowable limits of TSP, $\mathrm{PM}_{10}$ and $\mathrm{PM}_{2.5}$, respectively. These elevated levels might be attributed to various factors including; increased human activities (e.g. industries and traffic), frequent natural events (e.g. dust storms) and the significant influence of climate conditions (e.g. enhanced formation conditions of secondary particles with high temperatures and intense sunlight in addition to re-suspension of surface dusts in dry conditions).

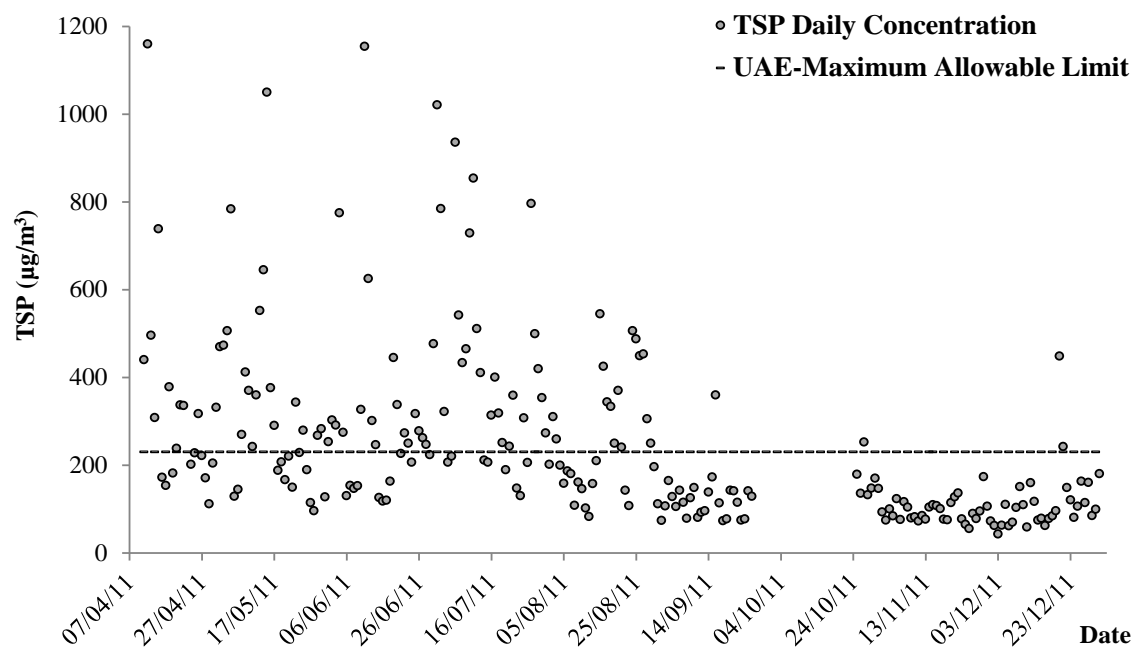

(a)

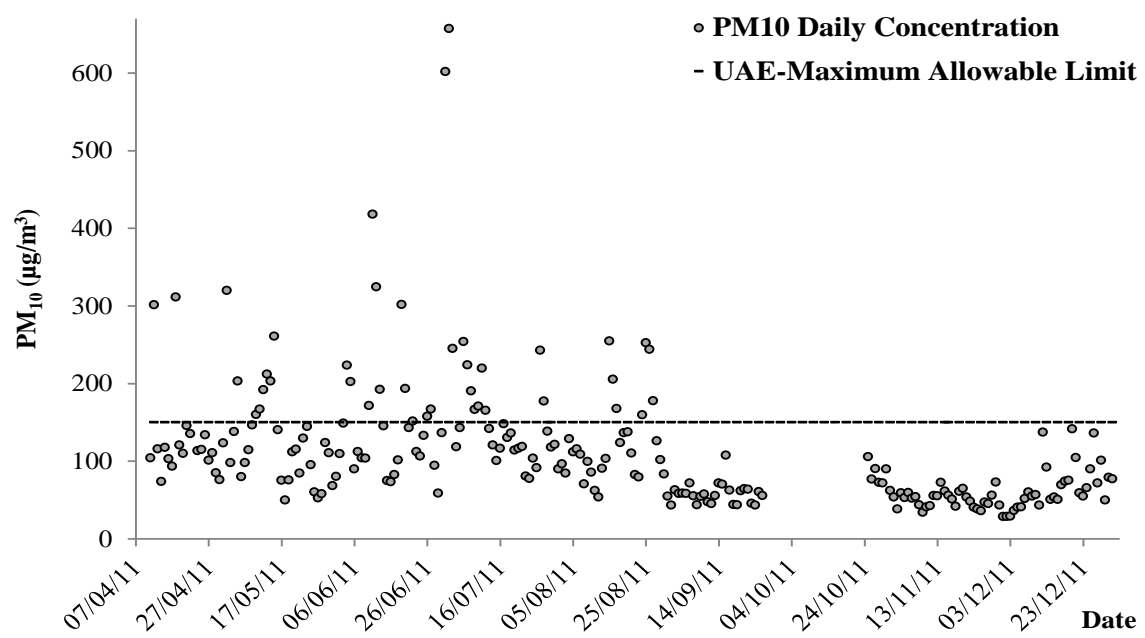

(b) 


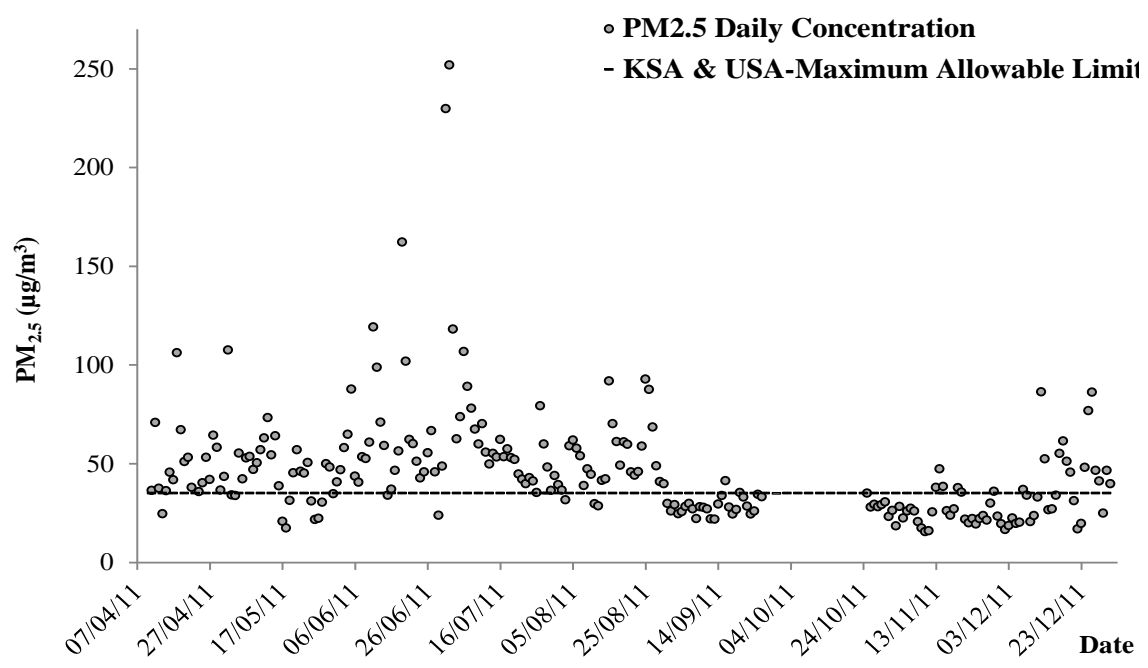

(c)

Figure 2. Daily mass concentrations of airborne particulates (a) TSP, (b) $\mathrm{PM}_{10}$ and (c) $\mathrm{PM}_{2.5}$.

\subsection{Temporal Variation of PM}

As it is obvious in Figure 3, the diurnal variation of PM with different size fractions did not follow a similar pattern because of their divergence characteristics as well as the variance of their behaviors in the atmosphere. The lowest levels of TSP and $\mathrm{PM}_{10}$ were observed during the early morning hours between 01:00 02:00 am, where the human activities are minimal and the climate is relatively cool, damp, with an eastern low-speed wind. After sunrise, the concentrations remarkably started to rise in conjunction with increased temperature and wind speed and reduced humidity, reaching primary and secondary peaks at 10:00 am and at 13:00 $\mathrm{pm}$ for $\mathrm{PM}_{10}$ and one hour later for TSP, and then began to decline. The rise in TSP and $\mathrm{PM}_{10}$ levels might be justified by a longer lifetime of particles at low humidity conditions, re-suspension of surface dusts by higher wind speed, and formation of secondary aerosols at high temperatures. The observed time lag between $\mathrm{PM}_{10}$ and TSP can be explained by the longer time required to transport larger and heavier particles by the wind, in addition to the contribution of the small particles that are agglomerated and coalesced to form greater ones over time. On the other hand, the least level of $\mathrm{PM}_{2.5}$ occurred at 12:00 noon associated with high temperature, low humidity, and moderate-speed western wind, and then $\mathrm{PM}_{2.5}$ level increased gradually to reach its peak at 04:00 am. The humid conditions are associated with high levels of $\mathrm{PM}_{2.5}$ which might be attributed to the role of moisture in forming secondary fine aerosol such as ammonium nitrate through the gas-to-particle conversion. Changes in prevailing wind directions have no noticeable effect on the average diurnal concentrations.

As illustrated in Table 3, the highest mean concentrations were observed on Saturdays for TSP and $\mathrm{PM}_{10}$ and on Sundays for $\mathrm{PM}_{2.5}$. On the other hand, the lowest levels were recorded on Thursdays for TSP and on Wednesdays for $\mathrm{PM}_{10}$ and $\mathrm{PM}_{2.5}$. The elevated $\mathrm{PM}$ levels during Saturday and Sunday might be attributed to the increased human and industrial activities during the free-time 




(a)



(b)

Figure 3. Diurnal variation patterns of the meteorological parameters and airborne particulates during the study period.

Table 3. Levels of airborne particulates $\left(\mu \mathrm{g} / \mathrm{m}^{3}\right)$ during the weekdays and weekends of the study period.

\begin{tabular}{cccccccccc}
\hline \multirow{2}{*}{ Day } & \multicolumn{4}{c}{ TSP } & \multicolumn{3}{c}{ PM $_{10}$} & \multicolumn{3}{c}{ PM $_{2.5}$} \\
\cline { 2 - 9 } & Min & Max & Mean \pm S.D. & Min & Max & Mean \pm S.D. & Min & Max & Mean \pm S.D. \\
\hline Sun & 27 & 2875 & $255 \pm 329$ & 23 & 714 & $119 \pm 92$ & 11 & 286 & $52 \pm 34$ \\
Mon & 35 & 2591 & $248 \pm 248$ & 27 & 736 & $120 \pm 94$ & 11 & 347 & $51 \pm 36$ \\
Tue & 21 & 3530 & $243 \pm 321$ & 20 & 709 & $106 \pm 73$ & 6 & 158 & $43 \pm 21$ \\
Wed & 28 & 3831 & $246 \pm 335$ & 14 & 712 & $98 \pm 71$ & 8 & 245 & $40 \pm 23$ \\
Thu & 20 & 2029 & $230 \pm 255$ & 19 & 473 & $99 \pm 67$ & 8 & 173 & $41 \pm 24$ \\
Fri & 27 & 4496 & $230 \pm 330$ & 12 & 967 & $107 \pm 112$ & 7 & 409 & $45 \pm 42$ \\
Sat & 27 & 3347 & $260 \pm 381$ & 16 & 927 & $121 \pm 131$ & 10 & 348 & $51 \pm 44$ \\
\hline
\end{tabular}

weekend (Saturday) and the first working day of the week (Sunday). As shown 
in Figure 4, relatively elevated concentrations were observed over extended time for the days of maximum records (Saturday for TSP and $\mathrm{PM}_{10}$ and Sunday for $\mathrm{PM}_{2.5}$ ) as compared with other days.

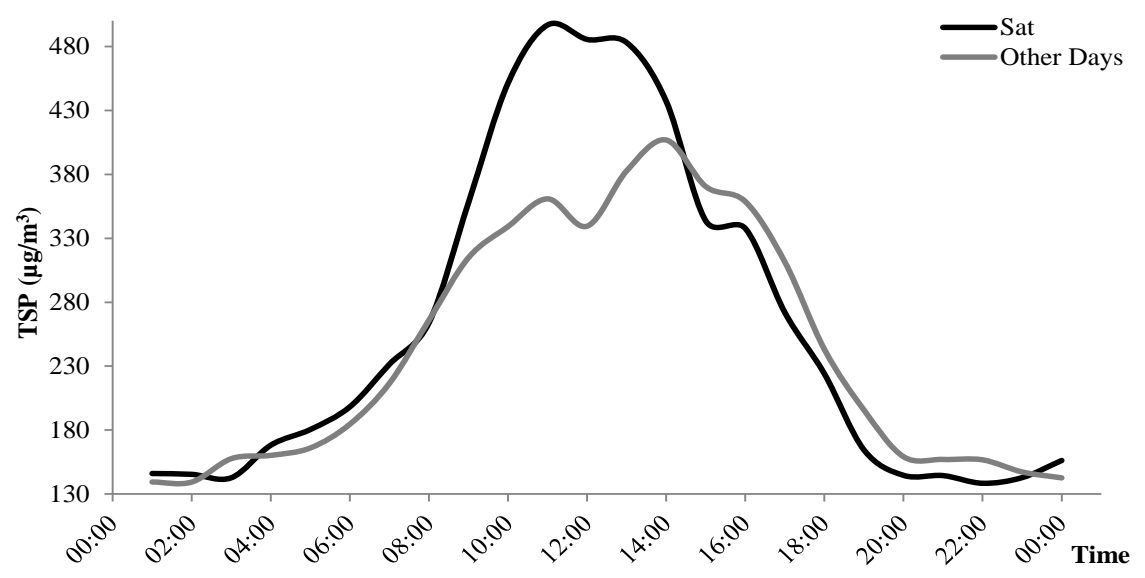

(a)

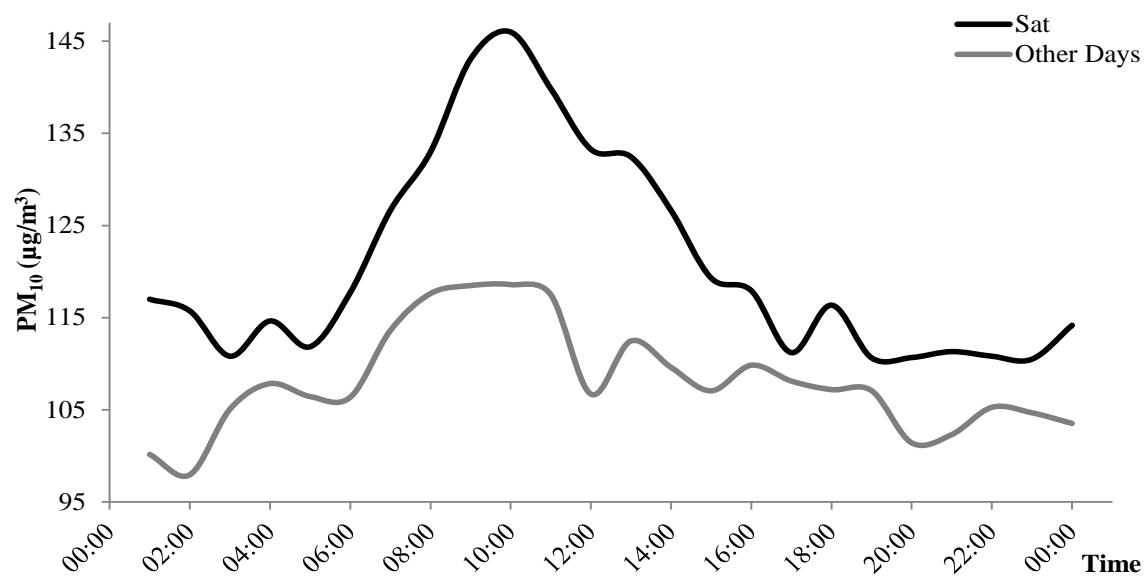

(b)

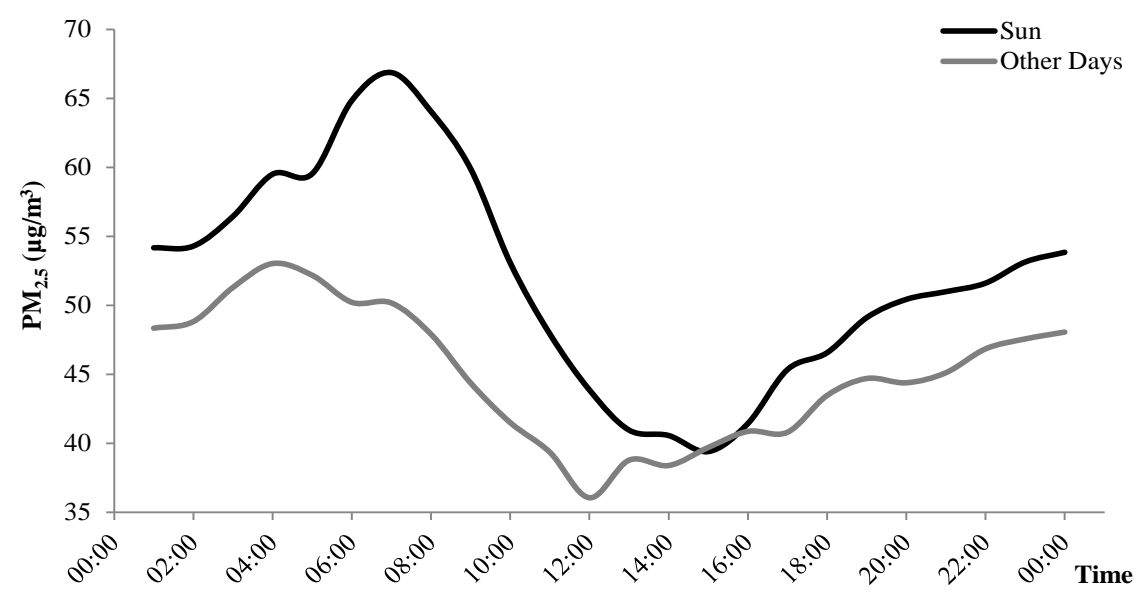

(c)

Figure 4. Diurnal variation patterns during the days when the maximum concentrations were observed as compared with other days for (a) TSP, (b) $\mathrm{PM}_{10}$ and (c) $\mathrm{PM}_{2.5}$. 
Monthly variations of PM mass concentrations are given in Table 4. The highest mass mean concentrations were observed for all size fractions in July primarily due to the frequent occurrence of dust storms during this period of time. The pattern of TSP during April to July is consonant with the wind speed pattern, which indicates that there is a notable influence of wind speed on large particulate levels. As expected, the lowest PM levels were recorded during the cool winter season as a result of the humid and occasionally rainy conditions. As presented in Figure 5, non-identical pattern of higher diurnal concentrations of particulate matters was observed during the summer months (April-August) as compared to the winter months (September, November and December).

Table 4. Monthly levels of airborne particulates $\left(\mu \mathrm{g} / \mathrm{m}^{3}\right)$ during the study period.

\begin{tabular}{cccccccccc}
\hline & \multicolumn{3}{c}{ TSP } & \multicolumn{5}{c}{ PM $_{10}$} & \multicolumn{3}{c}{ PM $_{2.5}$} \\
\cline { 2 - 9 } Day & Min & Max & Mean \pm S.D. & Min & Max & Mean \pm S.D. & Min & Max & Mean \pm S.D. \\
\hline Apr & 38 & 4496 & $345 \pm 449$ & 27 & 709 & $130 \pm 91$ & 12 & 159 & $49 \pm 28$ \\
May & 41 & 2875 & $331 \pm 358$ & 32 & 736 & $129 \pm 90$ & 8 & 269 & $46 \pm 27$ \\
Jun & 21 & 3347 & $307 \pm 348$ & 20 & 714 & $151 \pm 104$ & 18 & 286 & $61 \pm 37$ \\
Jul & 64 & 3831 & $415 \pm 422$ & 48 & 967 & $175 \pm 147$ & 19 & 409 & $70 \pm 55$ \\
Aug & 39 & 3248 & $256 \pm 269$ & 24 & 525 & $122 \pm 74$ & 12 & 185 & $52 \pm 24$ \\
Sep & 36 & 1291 & $124 \pm 137$ & 28 & 252 & $58 \pm 23$ & 14 & 72 & $28 \pm 8$ \\
Oct* & - & - & - & - & - & - & - & - & - \\
Nov & 20 & 710 & $95 \pm 62$ & 12 & 137 & $51 \pm 20$ & 6 & 85 & $26 \pm 13$ \\
Dec & 24 & 3530 & $115 \pm 157$ & 14 & 693 & $68 \pm 51$ & 8 & 347 & $38 \pm 27$ \\
\hline
\end{tabular}

${ }^{*}$ Data is not available from September $26,20: 00$ to October $24,14: 00$ due to power supply failure.

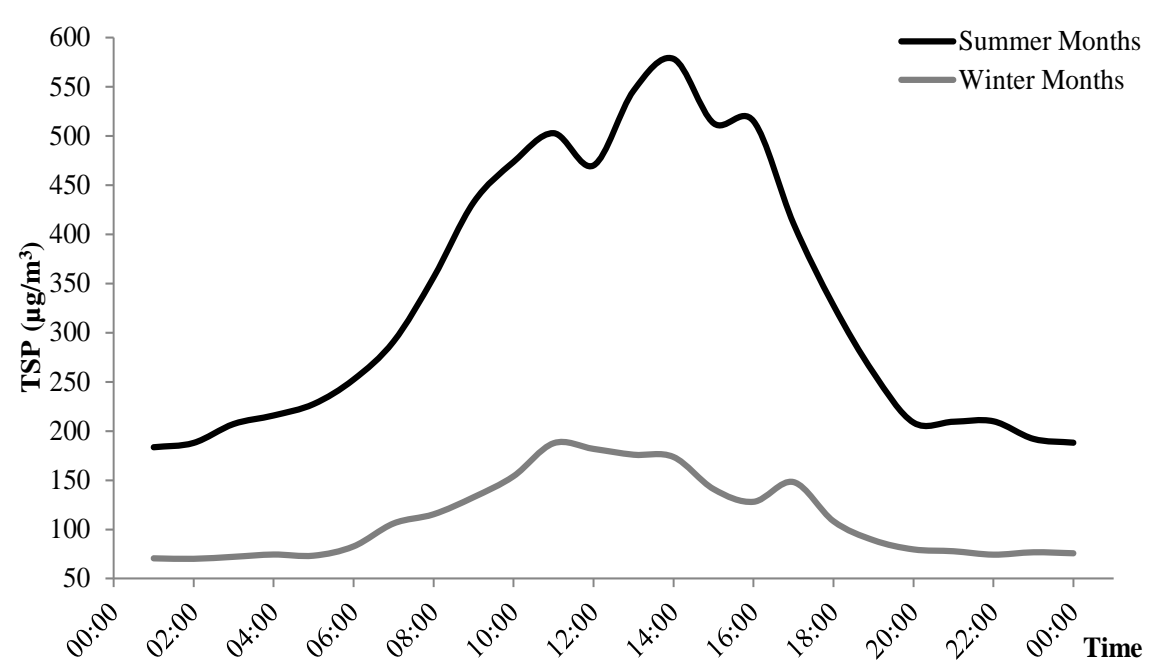

(a) 




(b)

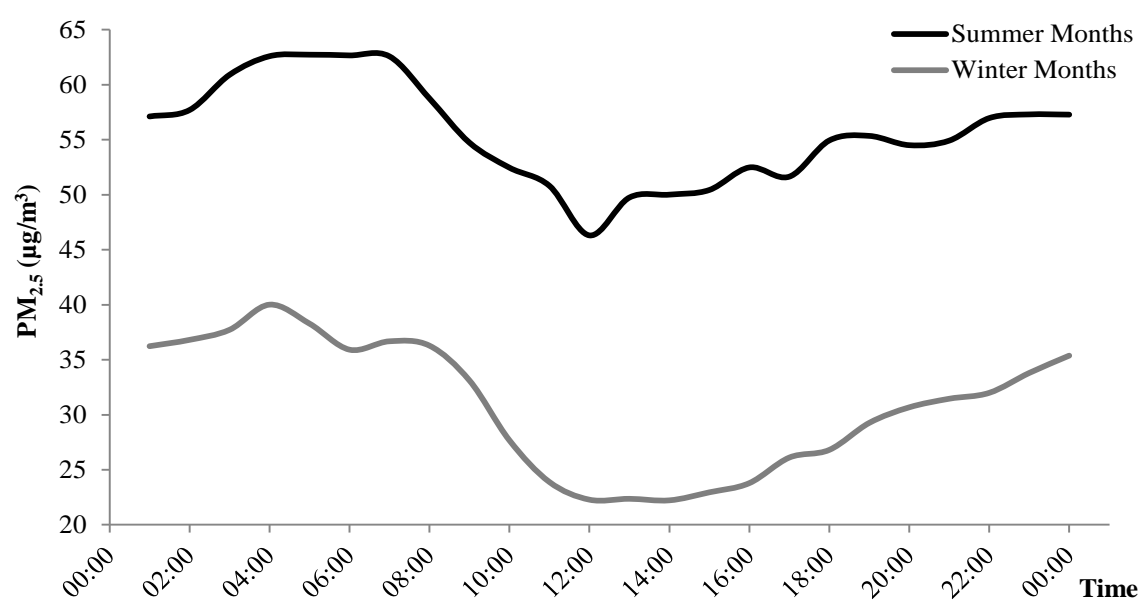

(c)

Figure 5. Diurnal variation patterns during summer and winter months for (a) TSP, (b) $\mathrm{PM}_{10}$ and (c) $\mathrm{PM}_{2.5}$.

\subsection{PM Mass Ratios}

Based on the mean ratio values shown in Table 5, TSP contains nearly $39 \%$ of particles with an aerodynamic diameter greater than $10 \mu \mathrm{m}\left(\mathrm{PM}_{>10}\right)$, and the rest $(61 \%)$ is $\mathrm{PM}_{10}$, which consists of $47 \% \mathrm{PM}_{2.5}$ and $53 \% \mathrm{PM}_{2.5-10}$. These results are inconsistent with the results of Engelbrecht et al. [24] for daily samples collected in the UAE, where the reported ratios of $\mathrm{PM}_{10} / \mathrm{TSP}$ and $\mathrm{PM}_{2.5} / \mathrm{PM}_{10}$ were 0.71 and 0.37 , respectively. The deviations between the obtained results and the above mentioned reported results by Engelbrecht et al. are mainly due to the influence of temporal and spatial variation in PM ambient levels. However, our results are closer to the typical $\mathrm{PM}_{2.5} / \mathrm{PM}_{10}$ ratio of 0.5 that have been documented for urban areas in developing countries [25], and reported for urban sites in Iran [26].

Table 5. Mass ratios between airborne particulate of different size fractions at the study area.

\begin{tabular}{cccccc}
\hline Datum & $\mathrm{PM}_{10} / \mathrm{TSP}$ & $\mathrm{PM}_{2.5-10} / \mathrm{TSP}$ & $\mathrm{PM}_{2.5} / \mathrm{TSP}$ & $\mathrm{PM}_{2.5-10} / \mathrm{PM}_{10}$ & $\mathrm{PM}_{2.5} / \mathrm{PM}_{10}$ \\
\hline Min & 0.09 & 0.05 & 0.02 & 0.06 & 0.18
\end{tabular}




\section{Continued}

\begin{tabular}{cccccc}
\hline Max & 1.00 & 0.65 & 0.94 & 0.82 & 0.94 \\
Mean \pm S.D. & $0.61 \pm 0.26$ & $0.30 \pm 0.13$ & $0.31 \pm 0.20$ & $0.53 \pm 0.15$ & $0.47 \pm 0.15$ \\
\hline
\end{tabular}

As shown in Table 6, very strong to moderate inter-correlations are found between PM of different size fractions. The weak correlations between total particle number and mass concentrations of particulate matter with different sizes indicate that the number of particles is an inadequate indicator of the mass levels and vice versa. The moderate correlation between TSP and wind speed is noticeable by the influence of wind on the diurnal variations of TSP. Figure 6 indicates that the highest average concentrations of airborne particulate are associated with wind coming from the south and south-southwest directions, where heavy highway traffic flow exists (re-suspension of surface dusts).

Table 6. Pearson correlation coefficient for airborne particulates and meteorological parameters during the study period.

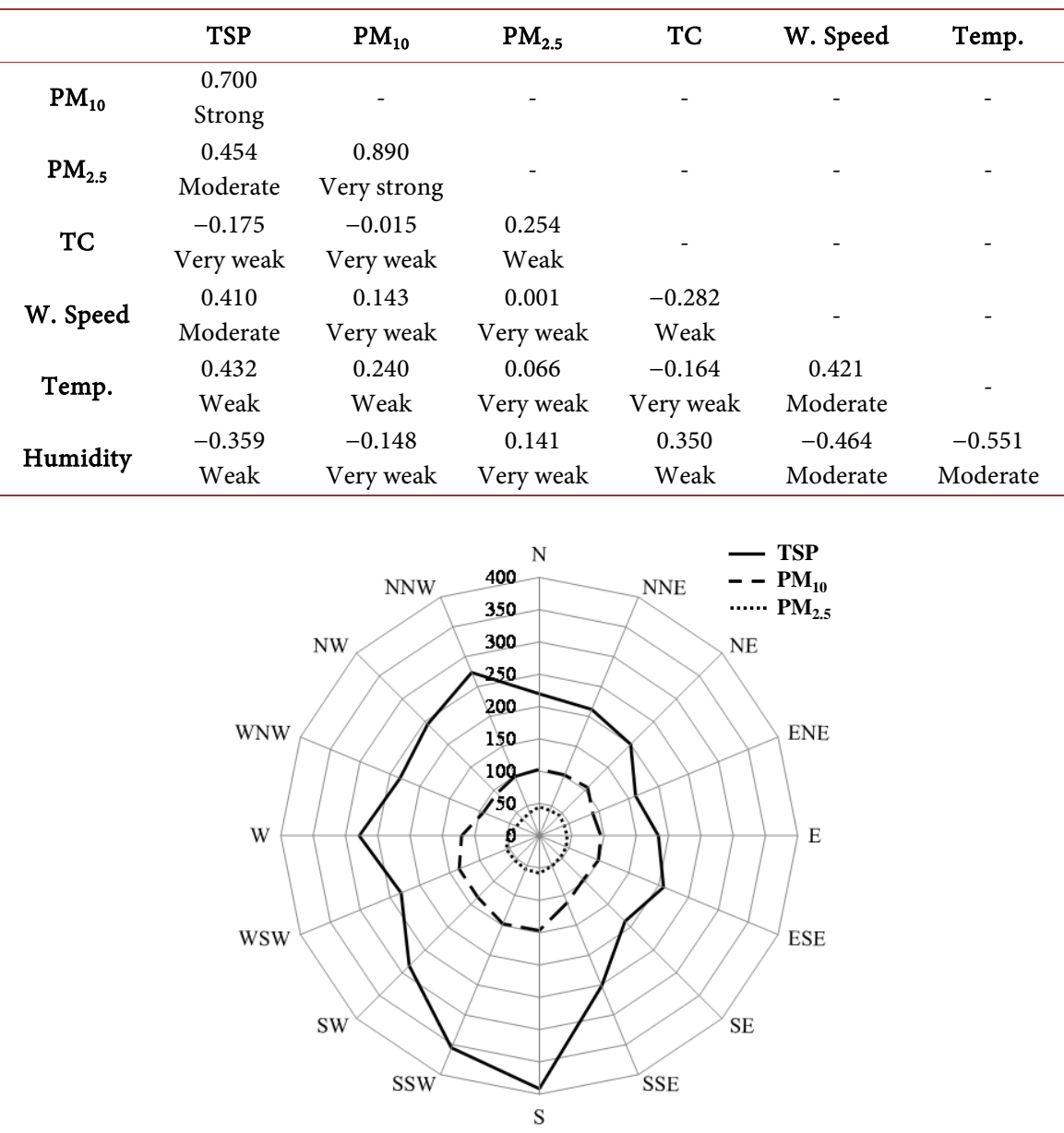

Figure 6. $\mathrm{TSP}, \mathrm{PM}_{10} \& \mathrm{PM}_{2.5}$ pollution rose at $\mathrm{Al}$ Samha during the study period.

\subsection{Measurement Techniques Comparison}

Measurement results of $\mathrm{PM}_{10}$ mass concentrations obtained by the light scattering 
spectrometer were compared with the concentrations measured by the beta attenuation monitor, as shown in Figure 7. Consequently, a correlation coefficient of $r=0.73$ (coefficient of determination $r^{2}=0.539$ ) indicates a strong linear relationship between the two measurement techniques. However, the $\mathrm{PM}_{10}$ mean value of the spectrometer results was $18 \%$ higher than its counterpart obtained by the beta attenuation monitor with the presence a statistically significant difference between the two data sets. This difference can be explained by the fact that both techniques may misestimate the actual concentrations [27] [28], and therefore their results need to be corrected by applying site specific and seasonal correction factors developed in line with the standard reference methods [29] which is beyond the scope of this study. However, TSP and $\mathrm{PM}_{2.5}$ results measured by the spectrometer are perfectly correlated $(r>0.995)$ with its counterparts obtained by gravimetric analysis of randomly collected samples as shown in Figure 8, noting that the spectrometer overestimated the TSP and underestimated the $\mathrm{PM}_{2.5}$ concentrations of the collected sample, especially at the high levels.



Figure 7. Comparison between $\mathrm{PM}_{10}$ concentrations measured by spectrometry and beta attenuation techniques.

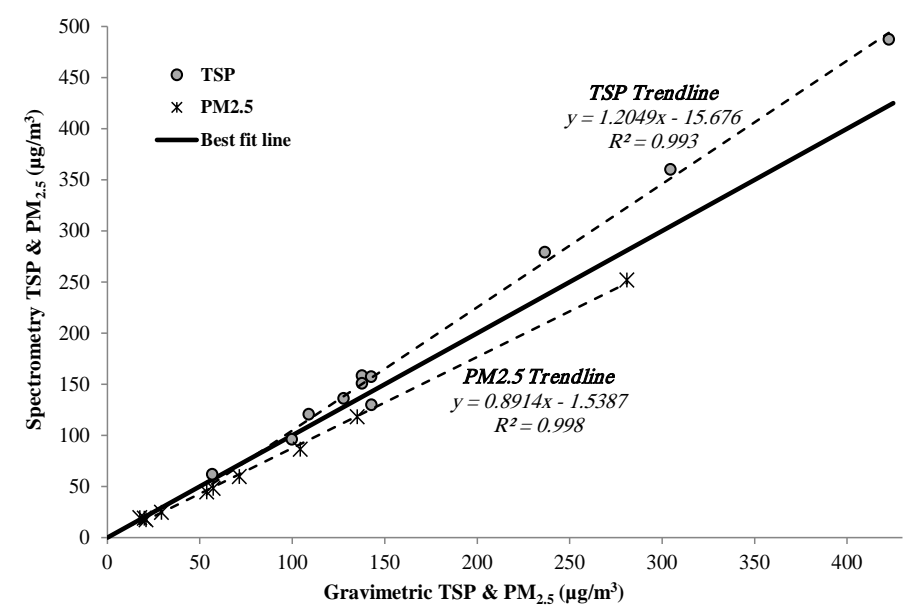

Figure 8. Comparison between TSP \& $\mathrm{PM}_{2.5}$ concentrations measured by gravimetric and spectrometry techniques. 


\section{Conclusions and Recommendations}

Based on the results of our study, the following major conclusions can be made:

- The study area experienced elevated levels of particulate matters, where the relevant maximum allowable limits were repeatedly violated. Therefore, long and short-term strategies should be implemented to reduce the levels of ambient particulate thereby improving the environment which in turn would enhance quality of human life.

- Diurnal peak occurred at 14:00 for TSP, at 10:00 for $\mathrm{PM}_{10}$, and at 04:00 for $\mathrm{PM}_{2.5}$. The diurnal variation of TSP had nearly a similar trend of $\mathrm{PM}_{10}$, but quite the opposite of the $\mathrm{PM}_{2.5}$ pattern. These trends might be justified by the varying effects of the atmospheric conditions on the levels of different-size particles, fluctuations of human activities, and the dynamic interaction with other pollutants.

- The most polluted days were Saturdays for the large particles (TSP \& $\mathrm{PM}_{10}$ ) and Sundays for fine particles $\left(\mathrm{PM}_{2.5}\right)$, while Thursdays and Wednesdays were relatively the cleanest days. That can be attributed to the traffic density alteration through the weekdays and its effect on the levels of ambient particulate matter.

- The highest levels for all PM size fractions were observed in July and the lowest levels were noted in November. This might be linked to several factors such as the roles of meteorological parameters in air quality, differences between daytime and night time with associated changes in human activities, varying climatic conditions, and the frequency of sandstorm occurrences.

- On average, the mass of suspended dust in the study area contained nearly $39 \%$ of large particles $\left(\mathrm{PM}_{>10}\right), 30 \%$ of coarse particles $\left(\mathrm{PM}_{2.5-10}\right)$, and $31 \%$ of fine particles $\left(\mathrm{PM}_{2.5}\right)$. On the other hand, $\mathrm{PM}_{10}$ consisted of $53 \% \mathrm{PM}_{2.5-10}$ and $47 \% \mathrm{PM}_{2.5}$.

- $\mathrm{PM}_{10}$ concentrations strongly correlated with TSP and $\mathrm{PM}_{2.5}$, but on the other hand TSP levels were moderately linked with $\mathrm{PM}_{2.5}$ and wind speed. In addition, the particle number concentration was found to be a poor indicator of the ambient levels of airborne particulates.

- The measurement results of the light scattering spectrometer strongly correlated with the values of the beta attenuation monitor, but the mean value of the spectrometer was higher by $18 \%$. Therefore, specific and seasonal correction factors should be developed and applied to the results of both investigated techniques based the standard reference methods.

In order to investigate the seasonal and the spatial variations, long-term measurements are recommended to be carried out at different locations. Short- and long-term strategies should be established and implemented to reduce the concentrations of anthropogenic and secondary PMs in ambient air, which can be achieved by controlling the stationary source emissions, developing an environmentally friendly transport system, raising public awareness of environmental issues, and expanding of green areas. 


\section{References}

[1] World Health Organization (WHO) (2014) 7 Million Premature Deaths Annually Linked to Air Pollution. Press Release, 25 March 2014.

[2] Organization for Economic Co-operation and Development (OECD) (2012) OECD Environmental Outlook to 2050: The Consequences of Inaction. OECD Publishing, Paris.

[3] European Science Foundation (ESF) (1998) Environment and Health Research for Europe: Scientists Recommendations. ESF Publishing, Strasbourg Cedex.

[4] El-Raey, M. (Ed.) (2006) Air Quality and Atmospheric Pollution in the Arab Region. ESCWA/League of Arab States, United Nations Environment Programme and Regional Office for West Asia.

[5] McKenzie, J.F., Pinger, R.R. and Kotecki, J.E. (2008) An Introduction to Community Health. 6th Edition, Jones and Bartlett Learning, Inc., Boston, MA, p. 464.

[6] Graff, D.W., Cascio, W.E., Rappold, A., Zhou, H., Huang, Y.T. and Devlin, R.B. (2009) Exposure to Concentrated Coarse Air Pollution Particles Causes Mild Cardiopulmonary Effects in Healthy Young Adults. Environmental Health Perspectives, 117, 1089-1094. https://doi.org/10.1289/ehp.0900558

[7] Tang, D., Wang, C., Nie, J., Chen, R., Niu, Q., Kan, H., Chen, B., Perera, F. and Taiyuan, C.D.C. (2014) Health Benefits of Improving Air Quality in Taiyuan, China. Environment International, 73, 235-242. https://doi.org/10.1016/j.envint.2014.07.016

[8] Cao, G. and Orrù, R. (Eds.) (2014) Current Environmental Issues and Challenges, Springer, Dordrecht, p. 19.

[9] Vallero, D. (2014) Fundamentals of Air Pollution. 5th Edition, Academic Press, London, p. 252.

[10] Schleicher, N.J. (2012) Chemical, Physical and Mineralogical Properties of Atmospheric Particulate Matter in the Megacity Beijing. KIT Scientific Publishing, Karlsruhe, p. 5.

[11] Gurjar, B., Molina, L.T. and Ojha, C.S.P. (2010) Air Pollution: Health and Environmental Impacts. CRC Press, Taylor \& Francis Group, Boca Raton, 250.

[12] Phalen, R.F. (2002) The Particulate Air Pollution Controversy: A Case Study and Lessons Learned. Kluwer Academic Publishers, Boston, 40.

[13] Cheremisinoff, N.P. and Rosenfeld, P.E. (2009) Handbook of Pollution Prevention and Cleaner Production Vol. 2: Best Practices in the Wood and Paper Industries. Elsevier, William Andrew, Burlington, 200.

[14] Buseck, P.R. and Schwartz, S.E. (2003) Tropospheric Aerosols. In: Turekian, K.K. and Holland, H.D., Eds., Treatise on Geochemistry, Vol. 4, Elsevier Science Ltd., 91-142.

[15] World Health Organization (WHO) (2013) Health Effects of Particulate Matter. Regional Office for Europe, Copenhagen.

[16] Schleicher, N.J. (2012) Chemical, Physical and Mineralogical Properties of Atmospheric Particulate Matter in the Megacity Beijing. KIT Scientific Publishing, Karlsruhe, 1.

[17] Ofosu, F.G., Hopke, P.K., Aboh, I.J.K. and Bamford, S.A. (2012) Characterization of Fine Particulate Sources at Ashaiman in Greater Accra, Ghana. Atmospheric Pollution Research, 3, 301-310. https://doi.org/10.5094/APR.2012.033 
[18] Hester, R.E. and Harrison, R.M. (1997) Air Quality Management. The Royal Society of Chemistry, Cambridge, 42.

[19] Yeatts, K., El-Sadig, M., Leith, D., Kalsbeek, W., Al-Maskari, F., Couper, D., Funk, W., Zoubeidi, T., Chan, R., Trent, C., Davidson, C., Boundy, M., Kassab, M., Hasan, M., Rusyn, I., Gibson, J. and Olshan, A. (2012) Indoor Air Pollutants and Health in the United Arab Emirates. Environmental Health Perspectives, 120, 687-694. https://doi.org/10.1289/ehp.1104090

[20] Al-Jallad, F., Al-Katheeri, E. and Al-Omar, M. (2013) Concentrations of Particulate Matter and Their Relationships with Meteorological Variables. Journal of Sustainable Environment Research, 23, 191-198.

[21] Nasser, Z., Salameh, P., Nasser, W., Abbas, L.A., Elias, E. and Leveque, A. (2015) Outdoor Particulate Matter (PM) and Associated Cardiovascular Diseases in the Middle East. International Journal of Occupational Medicine and Environmental Health, 28, 641-661. https://doi.org/10.13075/ijomeh.1896.00186

[22] Ministry of Energy (MoE) (2006) Initial National Communication to the United Nations Framework Convention on Climate Change. Ministry of Energy, United Arab Emirates.

[23] Campbell, M.J. and Swinscow, T.D.V. (2011) Statistics at Square One. 11th Edition, BMJ Books, Wiley-Blackwell Publishing, Oxford, 123.

[24] Engelbrecht, J.P., McDonald, E.V., Gillies, J.A., Jayanty, R.K.M., Casuccio, G. and Gertler, A.W. (2009) Characterizing Mineral Dusts and Other Aerosols from the Middle East-Part 1. Ambient Sampling, Inhalation Toxicology, 21, 297-326. https://doi.org/10.1080/08958370802464273

[25] World Health Organization (WHO) (2006) Air Quality Guidelines-Global Update. Particulate Matter, Ozone, Nitrogen Dioxide and Sulfur Dioxide. World Health Organization Regional Office for Europe, Copenhagen.

[26] Gholampour, A., Nabizadeh, R., Naseri, S., Yunesian, M., Taghipour, H., Rastkari, N., Nazmara, S., Faridi, S. and Mahvi, A.H. (2014) Exposure and Health Impacts of Outdoor Particulate Matter in Two Urban and Industrialized Area of Tabriz, Iran, Journal of Environmental Health Science and Engineering, 12, 1. https://doi.org/10.1186/2052-336X-12-27

[27] De Jonge, D. (2008) Field Experiment on 11 Automated PM Monitors. Technical Report, Department of Air Quality Research, Municipal Health Service, Amsterdam.

[28] Waldén, J., Hillamo, R., Aurela, M., Mäkelä, T., Laurila, S. and Institutet, M. (2010) Demonstration of the Equivalence of $\mathrm{PM}_{2.5}$ and $\mathrm{PM}_{10}$ Measurement Methods in Helsinki 2007-2008. Finnish Meteorological Institute.

[29] United States Environmental Protection Agency (US-EPA). Code of Federal Regulations, Title 40, Part 50, 40 CFR Part 50. Appendix B, Reference Method for the Determination of Suspended Particulate Matter in the Atmosphere (High Volume Method), Appendix J, Reference Method for the Determination of Particulate Matter as $\mathrm{PM}_{10}$ in the Atmosphere, and Appendix L, Reference Method for the Determination of Fine Particulate Matter as $\mathrm{PM}_{2.5}$ in the Atmosphere, USEPA, Washington DC. 
Submit or recommend next manuscript to SCIRP and we will provide best service for you:

Accepting pre-submission inquiries through Email, Facebook, LinkedIn, Twitter, etc. A wide selection of journals (inclusive of 9 subjects, more than 200 journals)

Providing 24-hour high-quality service

User-friendly online submission system

Fair and swift peer-review system

Efficient typesetting and proofreading procedure

Display of the result of downloads and visits, as well as the number of cited articles Maximum dissemination of your research work

Submit your manuscript at: http://papersubmission.scirp.org/

Or contact jep@scirp.org 